\title{
Non-formal Education Programmes and Poverty Reduction among Young Adults in Southern Senatorial District, Cross River State, Nigeria
}

\author{
Simon Ibor Akpama (Corresponding author) \\ Department of Adult and Continuing Education \\ Faculty of Education, University of Calabar \\ Calabar, Nigeria \\ E-mail: akpama2008@yahoo.com \\ Obal Usang Esang \\ Department of Adult and Continuing Education \\ Faculty of Education, University of Calabar \\ Calabar, Nigeria \\ Love Joseph Asor \\ Department of Adult and Continuing Education \\ Faculty of Education, University of Calabar \\ Calabar, Nigeria \\ William Otu Osang \\ Department of Adult and Continuing Education \\ Faculty of Education, University of Calabar \\ Calabar, Nigeria
}

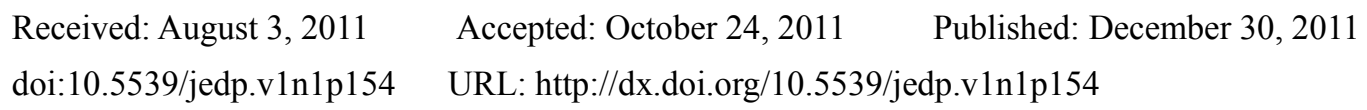

\begin{abstract}
The study investigated the influence of non-formal education programmes on poverty reduction among young adults in southern senatorial district of Cross River State, Nigeria between 2000-2005. Three hypotheses were postulated and tested. Data were collected using the Poverty Reduction Inventory (PRI). The stratified random sampling technique was used based on location (Local Councils and existing political wards) to select four local government areas and forty local wards. From these local government areas and wards, simple random sampling technique was employed to select two local government areas and thirty wards from which three hundred (300) youths were selected as sample for the study. Data collected were analysed using analysis of variance and independent t-test analysis. Results obtained showed that acquisition of vocational skills lead to a significant reduction of poverty among young adults, and participants' age on skill acquisition programmes significantly, influenced poverty reduction. Similarly, the results revealed that there is no significant difference in poverty reduction between male and female youths. On the basis of these findings recommendations were made.
\end{abstract}

Keywords: Non-formal education, Poverty reduction, Young adults

\section{Introduction}

Non-formal education according to Combs, Prosser and Ahmed (1973) cited in Preece (2009) refers to any 
organised educational activity outside the established formal system that is intended to serve identifiable clienteles and learning objectives. It encompasses a wide range of activities and often acts as an umbrella concept for a range of differently named programmes ranging from complementary basic education to vocational, community and popular education (Car-Hill, Carron and Peart, 2001).

In Nigeria, the modernised form of non-formal education which was implemented in collaboration with UNICEF was introduced in 1995. The thrust of the programme was to provide basic education and vocational education to the underlisted groups of people:

i. persons who could not find a place within the formal school system

ii. persons who dropped out of school

iii. persons with ardent interest in improving themselves educationally and improving their skills.

While UNICEF focused on saving the supply of basic education from total collapse, the Federal Government of Nigeria viewed the project from a dual perspective, that is saving it from total collapse and providing skills for poverty reduction. Against this backdrop, the Obasanjo led administration in 1999 signed the Universal Basic Education (UBE) law to bring basic literacy to the poor, and this was complemented with the Poverty Alleviation Programmes (PAP) and the National Economic Empowerment Development Strategy (NEEDS).

In consonance with this project, different states in Nigeria and local councils implemented the State Economic Empowerment Development Strategy (SEEDS) and Local Economic Empowerment Development Strategy (LEEDS) respectively. The essence of this non-formal education project was to empower youths by providing them with vocational skills germane to poverty reduction within their social and cultural contexts. This project provoked the researchers' interest to investigate the possible influence of these non-formal education programmes on poverty reduction among youth adults in the Southern Senatorial District of Cross River State, Nigeria.

\subsection{The Problem}

Within the long years of military rule in Nigeria spanning 1960 to 1999 , poverty had over ran the country due to neglect and corruption. Many youths became restive crime prone and violent, since many of them dropped out of school or completed school without any gainful employment. The previous educational experiences of these youths did not equip them with vocational skills to assuage their impoverished conditions.

In order to attenuate this situation, the Cross River State government waged war against poverty through the provision of various training programmes using adult education structures in the state. The efficacy of these programmes as potent poverty reduction vehicles must be ascertained. Therefore, the researchers investigated the extent to which these non-formal education programmes have contributed to the reduction of poverty among the youths in the study area.

\subsection{Hypotheses}

1) Skills acquisition has no significant influence on poverty reduction among young adults;

2) Participants' age on skill oriented programmes does not significantly influence poverty reduction among young adults;

3) There is no significant difference in poverty reduction between male and female youths.

\subsection{Limitation of the Study}

The study only focus on five core areas of tailoring, fishing, beads making, hair dressing and soap making among young adults in the study area. In essence other skills like plumbing, welding, baking, metal work and refrigerator repairs prevalent in vocation skill acquisition centres located in other senatorial district were not studied in this present investigation, hence the limitation of the generalization of these findings to other senatorial districts of the state.

\section{Literature Review}

According to Biao (1994) \& Akpama (2001) the primary mission of non formal education is to provide education and training that is accessible to out-of-school learners and to create opportunities for acquisition of life skills to enable individuals to attain their full potential and contribute to the socio-economic advancement of their immediate communities and to national development.

The purpose of non-formal education in the afore-stated excerpt, shows its relevance to poverty reduction. In the same vein, UNESCO (2006:39) conceptualizes Non-formal education as an integrated approach that takes into 
account all the factors influencing the opportunities and life chances of different population groups and the role played by education systems themselves in the process of social inclusion and cohesion. It is learning embedded in planned, organized and sustained education activities that are outside formal education institutions, responding to education needs for all persons of ages. The purpose of NFE is to provide alternative learning opportunities for those who do not have access to formal schooling or need specific life skills and knowledge to overcome different obstacles. Non-formal learning is also intentional from the learner's point of view, as opposed to incidental or random types of learning.

The essence of non-formal education in this context is to provide learning opportunities meant to equip learners with requisite skills to alleviate their poverty stricken conditions (Akpama, $2001 \&$ Preece, 2009).

Ngwu (2003) also describes non-formal education as any planned and consciously organized general education and/or training activity outside the formal school in a particular society for illiterates, school leavers, drop-outs, or other adults, as individuals or in groups, for the purpose of raising their consciousness of their social situation and their standard of living, improving their individual or collective efficiency in their jobs, or preparing them for self employment wage, employment or further training within the existing education/learning system (P.18).

The need to improve the employment and income generating potential of these learners is imperative if poverty must be reduced. These programmes designed to alleviate poverty must enhance capacities for employment and income generation through acquisition of life skills.

\subsection{Non-formal Education Programmes and Poverty Reduction in Cross River State}

In Cross River State, Nigeria, poverty has been considered primarily in terms of economic and materials insufficiencies (Biao, Akpama \& Okukpon; 2009:91). It implies lack of access (freedom) to three square meals, poor health, and inability to generate income beyond existing livelihood levels. Many youths and adults lack employment and income generating opportunities hence, the restiveness and incessant cases of armed robbery and clashes between security operatives and criminals.

In order to assuage this ugly trend, the Cross River State Government implemented the State Economic Empowerment Development Strategy (SEEDS) and the Local Government Economic Empowerment Development (LEEDS). These, non-formal which is also vocational skill acquisition programmes seek to equip its clienteles with different vocational skills. Similarly, the National Directorate of Employment (NDE) and the Niger Delta Development Commission (NDDC) float a variety of skill acquisition programmes in tailoring, welding, soap making, hair-dressing, baking, metal work, refrigerator repairs and computer engineering and so on.

Those programmes are meant to equip young people and adults with employment and income generating skills for poverty reduction in the Southern Senatorial District of the state.

Furthermore, the Cross River State Community Based Poverty Reduction Project (CPRP) was introduced and implemented to mobilize and prioritize needs, decision-making implementation, monitoring and maintenance of assets established by the projects. The project has the following objectives:

i. building on the coping mechanisms of the poor and taking into account the cultural and social factors that influence these mechanisms

ii. enhancing the ability of the poor to help themselves on a sustained basis through capacity building

iii. empowering the poor by increasing their participation in decision making at community and local government levels

iv. raising the living standards of the poor through cost effective target and demand driven projects (Iwuchukwu, 2002).

The need to ascertain the influence of these non-formal education programmes on poverty reduction among the youths prompted this investigation.

\subsection{Sex, Skill Acquisition and Poverty Reduction}

Thomas, F., Anne, K. \& Akpovire, O. (2005) cited in Essang (2008) assert that no factor exerts more influence on one's overt behaviour, his emotional reaction, his cognitive functions, his convert attitudes and his general psychological adjustment, than his sex. Abramson (1980:307) opined, that "one's sex will determine his friends, his parental relationship, his jobs, his role in the family and hobbies".

In terms of vocational interest, Onyejiaku (1985) states that young male adults are more vocationally mature than girls, while the boys become more involved in making career decisions, girls are drawn towards marriage. 
Osuala (1998) referred to skill as the ability to perform expertly, facility in performance, dexterity and tact. It is therefore training given to an employee, or learner to make him perform more expertly on his job by using his knowledge effectively and readily in execution of his assigned duties. Biao (1994) maintained that "non-formal education has the potential for improving the skill of an individual (male and female) on an already chosen trade or practices while simultaneously, equipping this individual with new attitudes, knowledge and skills". Preece, J and Singh, (2003) maintained that investing in the education of girls and women especially widows results in positive returns to the learners themselves and society as a whole. However, it is observed that the outcome of skill acquisition whether male or female leads to poverty reduction.

\section{Research Methodology}

This study was conducted in the Southern senatorial district of Cross River State, Nigeria. The Southern senatorial district is one of the three Districts in the state. Others are Central and Northern senatorial districts.

The design adopted for this study was ex post facto. Three hypotheses were formulated to guide the study. Ten vibrant skill acquisition centres where SEEDS and LEEDS programmes are implemented were identified in the study area, made up of six (6) state owned and 4 privately owned. Five skill areas (tailoring, fishery, bead making, hair dressing and soap making) were deliberately chosen for investigation because these form the core curriculum contents of the vocational or non-formal education programmes of the government in the study area. The population consisted of all young adults involved in skill acquisition programmes in the study area. Precisely, 410 young adults constituted the population. Stratified random sampling technique was employed to draw the skill acquisition centres to constitute the sample. The same method was used to select 5 skill acquisition centres from the study area. In each of these skill acquisition centres sixty (60) participants were randomly drawn which summed up to three hundred (300) participants with ages between 15-30 years. A further breakdown of the sample showed that there were two hundred (200) males and one hundred and (100) females. This disparity was due to the higher number of male unemployed and restive youths in the area. The researchers constructed an instrument christened Poverty Reduction Inventory (PRI) which was used for data collection.

The instrument had two sections - A and B sections. Section A had seven (7) demographic variables while section B contained twenty five (25) items on a rating scale. These various instruments were validated by experts in measurement and evaluation, while the trial test yielded reliability coefficients ranging from 0.97 to 0.98 . Three hundred (300) copies of the questionnaire were statistically treated using Analysis of Variance (ANOVA) and Independent t-test statistical analyses.

\section{Results}

\subsection{Hypothesis 1}

Skill acquisition has no significant influence on poverty reduction among young adults. To test this hypothesis, five (5) skills acquisition trades were presented to the respondents, for them to rate the extent to which each of these skills they have acquired has been able to reduce their poverty. Items on poverty reduction were measured on a 4 point Likert scale and the sum of all the twenty-five (25) items constitutes poverty reduction for the respondents. The one way analysis of variance (ANOVA) was employed to test the hypothesis as presented in tables 1 and 2.

Table 1 shows the group mean and standard deviation of the five (5) skills acquired for poverty reduction, while Table 2 shows the actual results of the analysis of variance.

Table 2 shows the result of the one-way analysis of variance of the influence of skill acquisition on poverty reduction among young adults. The result gave an F-ratio of 4.31. This value at .05 level of significance with 4 and 295 degrees of freedom is higher than the critical F-ratio of 2.54. From the result of data analysis with respect to poverty reduction, the null hypothesis was rejected. This implies that there is a significant influence of skill acquisition on poverty reduction among young adults in the study area.

The pattern of this significant influence of skill acquisition on poverty reduction of young adults is further explored with Fisher's least significant difference (LSD) Post-Hoc multiple comparison analysis. The results of these analyses are presented in Table 3.

Table 3 shows that soap making, hairdressing, bead making and fishery are skills that lead to significant reduction of poverty. A comparative analysis shows that tailoring reduces poverty more significantly than fishery and beadmaking. On the other hand, soap making and hairdressing are more significant in poverty reduction than fishery. Moreso, soap making and hairdressing reduces the poverty level of young adults much more than bead making. 


\subsection{Hypothesis 2}

Participants' age on skill oriented programmes has no significant influence on poverty reduction among young adults.

The independent variables in this hypothesis are participants' age and the dependent variable is poverty reduction among young adults. To test this hypothesis, the respondents whose ages are 15-19, 20-24 and 25-30 were to rate the extent to which their poverty has been reduced by the acquired skills. The poverty reduction has a 4-point likert scale and the sum for all the twenty-five (25) items constitute poverty reduction for the respondents.

The statistical analysis technique employed to test this hypothesis was one way analysis of variance (ANOVA). The results of the analysis are presented in Tables 4 and 5 . Table 4 shows the group mean and standard deviation of the ages. Table 5 shows the actual results of the analysis of variance.

Table 5 shows the result of the one-way analysis of variance of the influence of participants' age on skill oriented programmes and poverty reduction among young adults. The result gave an F-ratio of 7.40. From the results of data analysis the null hypothesis was rejected. This implies that there is a significant influence of participants' age on skill oriented programmes and poverty reduction among young adults.

To see the direction of influence o Post-Hoc test using the Fisher's Least Significant Difference (LSD) test was performed as presented in table 6 .

The tables reveal that poverty reduction of youths between the ages of 25-30 years is significantly higher than those of 20-24 years and highest for these of ages between 15-19 years.

\subsection{Hypothesis 3}

There is no significant difference in poverty reduction between male and female youths.

The independent variable in this hypothesis is gender (male and female) and the dependent variable is poverty reduction among young adults. To test this hypothesis male and female respondents were to rate the extent to which their poverty has been reduced by their acquired skill. Poverty reduction had a 4-point scale and the sum for all the twenty-five (25) items constitute poverty reduction for the respondents.

The statistical analysis technique implored to test this hypothesis was independent t-test. The result of the analysis is presented in table 7 .

The result presented in table 7 shows that the calculated $t$-value of -1.85 is less than the critical value of -1.96 at .05 level of significance. This implies that there is no significant difference in poverty reduction between male and female young adults in the study area.

\subsection{Discussion}

The result of hypothesis one revealed that skills acquisition significantly influences poverty reduction among young adults. The results went further to show the pattern of the significant influence through the comparative analysis which shows that tailoring reduces poverty more significantly than fishery and beads-making. Also, that soap-making and hairdressing are more significant in poverty reduction than fishery. And, moreso, soap-making and hairdressing reduce poverty much more than beads-making in the study area.

Thus, all the identified skills are potential poverty reduction trades. This underscores the fact that the poverty reduction agency and women development centres had carried out detail study of such trades that could actually affect the lives of the poor. Thus, poverty reduction programme is a success and is dependent on the skill acquired.

In corroborating this finding, Biao (1994) and Preece (2009) maintained that non-formal education programmes have the potential of improving the skills of an individual on an already chosen trade or practice while, simultaneously, equipping this individual with new attitudes, knowledge and skills. Moreso, the Encyclopaedia Americana (International edition, 1991) corroborates the fact that vocational education aims at preparing young people and adults for useful occupations, particularly skilled trades and semi-professional careers. The acquisition of these skills enhances self-employment which cushions the adverse effect of unemployment in the society.

The results of hypothesis two showed that there is a significant influence of age on poverty reduction among young adults. The result further reveals that poverty reduction of youths between the ages of 25-30 years is significantly higher than those of 20-24 years and highest for those of ages between 15-19 years.

This is not surprising because people within the age bracket of 25-30 years can fend for themselves, whereas, those between the ages of 15-19 years are categorized as dependents in the study area. The same is true for those 
within the age bracket of 20-24, although much less.

Therefore, the older the youths, the more independent and the more conscious they would want their poverty to be reduced by themselves using any available opportunity.

To support this assertion, statistics obtained from FOS, National Census Survey of 1999 showed that young adults between 15-35 years of age showed a percentage of the poor people to be $37.4 \%-64.6 \%$. Also, Adegoke (2004) maintained that although poverty permeates every demographic group, it is much more severe and has a wider implication among the aged.

The result of the third hypothesis revealed that there is no significant difference in poverty reduction between males and females young adults.

Thus, poverty is a respecter of nobody whether male or female. To this end, the poverty reduction indices do not discriminate between male and female. However, Awoseyila (1999) asserted that gender related poverty headcount showed more severe poverty level with male headed households than female-headed ones. However, evidences abound that more females-headed households are more vulnerable to poverty than male headed households (Oladunni, 1999).

\section{Conclusion and Recommendations}

Arising from these findings, the investigators concluded that skill acquisition significantly influence poverty reduction among young adults in the study area.

Also that age of participants exerts enormous influence on skill acquisition and subsequently poverty reduction. Similarly the investigation showed that significant difference was not found in poverty reduction between male and female young adults in the study area.

Therefore the researchers recommended that graduands of these poverty alleviation programmes should be provided with more credit facilities to facilitate the establishment of businesses outfit for self employment job creation and improve income generation to achieve the goal of poverty reduction.

\section{References}

Abramson, P.R. (1980). Personality. New York: Rinehart and Winston.

Adegoke, A.T. (2004). Poverty Alleviation: The social-economic implications on the aged in Uyo Local Government. Unpublished Ph.D seminar paper. Uyo: University of Uyo.

Akpama, S.I. (2001). Functional literacy: A Panacea for poverty eradication in the $21^{\text {st }}$ century. Education for Today Journal of Faculty of Education, 2 (1), 77-85.

Awoseyila, A.P. (1999). The dimensions of poverty in Nigeria. Bullion, 23 (4), 31-39.

Biao, I. (1994). Background to the introduction of UNICEF non-formal education in Nigeria education curriculum into Nigeria. Calabar: University of Calabar Press.

Biao, I., Akpama, S.I., Tawo, R.E., \& Okukpon, L. (2009). Case study of two non-formal programmes in Cross River State, Nigeria in Preece J. (Ed) Non-formal education, poverty reduction and life enhancement: a comparative study. Botswana: Lightbooks Limited.

Carr-Hill, R., Carron, G., \& Peart, E. (2001). Classifying out-of-school education in Watson, K. (ed.). Doing Comparative Research, 331-354.

COMBS, p. (1973). Now paths to learning for rural children and youths. New York: International Council for Education Development.

Esseng, O. (2008). Non-formal education programmes and poverty reduction in Cross River State. Unpublished M.Ed Thesis, Calabar: Department of Adult and Continuing Education, University of Calabar.

Federal Office of statistics (1999). Poverty profile for Nigeria (1980-1996) Abuja: Federal office of statistics Press.

Iwuchukwu, C., \& Ukwayi, J. (2002). A key note address by the General Manager, Cross River Stat Community based Poverty Reduction Agency on the occasion of the distribution and contributions of the first batch approved community based sub-projects in Calabar, April.

Ngwu, P.N.C. (2003). Non-formal Education, Concepts and Practices. Enugu: Fulladu Publishing Company.

Onyejiaku, F.U. (1985). Intra sex differences in Vocational maturity of Nigerian adolescents. The Nigeria Journal of Guidance and Counselling, 514, 76-79. 
Osuala, E.C. (1998). Foundations of Vocational Education. Onitsha: Cape Publishers International.

Preece, J., \& Singh, M. (2003: March) Adult learning and poverty reduction. Thailand: CONFINTEA \& Midterm review conference.

Preece, J. (2009). Conceptual framework for non-formal education and poverty, in Preece, J. (Ed), Non-formal education poverty reduction and life enhancement: a comparative study. Botswana: Lightbooks Limited.

UNESCO (2006). Synergies between formal and non-formal education: An overview of good practices. Bonn: UNESCO/UIE.

Table 1. Mean and standard deviation of skill acquisition for poverty reduction

\begin{tabular}{|l|c|c|c|}
\hline Group & $\mathrm{N}$ & Mean & SD \\
\hline Tailoring & 91 & 65.52 & 12.63 \\
Fishery & 38 & 60.76 & 13.49 \\
Beadmaking & 51 & 59.78 & 8.95 \\
Hairdressing & 82 & 66.24 & 11.32 \\
Soap-making & 38 & 67.58 & 9.91 \\
Total & $\mathbf{3 0 0}$ & $\mathbf{6 4 . 3 7}$ & $\mathbf{1 1 . 7 6}$ \\
\hline
\end{tabular}

Table 2. Analysis of variance of skills acquired for poverty reduction

\begin{tabular}{|l|c|c|c|c|}
\hline Source of variation & Sum of square & $\mathrm{df}$ & Mean square & f-ration \\
\hline Between groups & 2282.23 & 4 & 570.56 & $4.31^{*}$ \\
Within groups & 39100.21 & 295 & 132.54 & \\
Total & $\mathbf{4 1 3 8 2 . 4 4}$ & $\mathbf{2 9 9}$ & & \\
\hline
\end{tabular}

Significant at .05 level (critical F $4_{295}=2.54$ )

Table 3. Fisher's least significance difference (LSD) multiple comparison analysis of the influence of kill acquisition on poverty reduction of young adults

\begin{tabular}{|l|c|c|c|c|c|}
\hline Skill acquisition & $\begin{array}{c}\text { Tailoring } \\
(\mathrm{n}=91)\end{array}$ & $\begin{array}{c}\text { Fishery } \\
(\mathrm{n}=38)\end{array}$ & $\begin{array}{c}\text { Beadmaking } \\
(\mathrm{n}=51)\end{array}$ & $\begin{array}{c}\text { Hairdressing } \\
(\mathrm{n}=82)\end{array}$ & $\begin{array}{c}\text { Soapmaking } \\
(\mathrm{n}=38)\end{array}$ \\
\hline Tailoring & $65.52^{\mathrm{a}}$ & $4.76^{\mathrm{b}}$ & 5.74 & -.72 & -1.71 \\
\hline Fishery & $2.07^{\mathrm{ac}}$ & 60.76 & .98 & -5.48 & -6.47 \\
\hline Beadmaking & $2.88^{*}$ & .38 & 59.78 & -6.46 & -7.45 \\
\hline Hairdressing & -44 & $-2.38^{*}$ & $-3.24^{*}$ & 66.24 & -.99 \\
\hline Soapmaking & -.74 & $-2.29^{*}$ & $-2.90^{*}$ & -.43 & 67.23 \\
\hline
\end{tabular}

$\mathrm{SW}=132.54$

$=$ Group means are along the diagonal

$=$ Difference among groups are above diagonal

$=$ Fisher's t-value are below the diagonal

Alt $=1.96$ at .05 level 
Table 4. Mean and standard deviation of the influence of ages on poverty reduction

\begin{tabular}{|l|c|c|c|}
\hline Age (Years) & $\mathrm{N}$ & Mean & SD \\
\hline $15-19$ & 32 & 58.75 & 7.91 \\
\hline $20-24$ & 80 & 62.35 & 11.28 \\
\hline $25-30$ & 188 & 66.20 & 12.11 \\
\hline Average & $\mathbf{1 0 0}$ & $\mathbf{6 4 . 3 8}$ & $\mathbf{1 1 . 7 6}$ \\
\hline
\end{tabular}

Table 5. Analysis of variance of the influence of age on participation of skill oriented programmes on poverty reduction

\begin{tabular}{|l|c|c|c|c|c|}
\hline \multicolumn{1}{|c|}{ Source of variation } & Sum of square & df & Mean square & f-ratio & sig \\
\hline Between groups & 1964.52 & 2 & 982.26 & $7.40^{*}$ & 0.001 \\
\hline Within groups & 39417.92 & 297 & 132.72 & & \\
\hline Total & $\mathbf{4 1 3 8 2 . 4 4}$ & $\mathbf{2 9 9}$ & & & \\
\hline
\end{tabular}

Significant at .05 level

Table 6. Fisher's least significance difference (LSD) of the influence of age on participation of skill oriented programmes and poverty reduction among young adults

\begin{tabular}{|l|c|c|c|}
\hline Skill acquisition & $15-19$ yrs $(\mathrm{n}=32)$ & $20-24$ yrs $(\mathrm{n}=80)$ & $25-30 \mathrm{yrs}(\mathrm{n}=188)$ \\
\hline $15-19$ years & $58.75^{\mathrm{a}}$ & $-3.60^{\mathrm{b}}$ & -7.45 \\
\hline $20-25$ years & $-1.55^{\mathrm{c}}$ & 62.35 & -3.85 \\
\hline $25-30$ years & $3.39^{*}$ & $-2.23^{*}$ & 66.20 \\
\hline
\end{tabular}

$\mathrm{SW}=132.72$

$\mathrm{a}=$ Group means are along the diagonal

$\mathrm{b}=$ Difference among groups are above diagonal

$\mathrm{c}=$ Fisher's t-value are below the diagonal

critical $\mathrm{t}=1.96$ at .05 level

Table 7. Independent t-test analysis of poverty reduction between male and female youths

\begin{tabular}{|l|c|c|c|c|c|}
\hline Sex & $\mathrm{N}$ & Mean & $\mathrm{SD}$ & t-value & Sig \\
\hline Poverty reduction male & 96 & 62.55 & 12.31 & & \\
\hline & & & & $-1.85^{*}$ & .818 \\
\hline Female & 204 & 65.24 & 11.43 & & \\
\hline
\end{tabular}

*Not Significant at .05 level 